University of Nebraska - Lincoln

DigitalCommons@University of Nebraska - Lincoln

Faculty Papers and Publications in Animal

Science

Animal Science Department

June 2004

\title{
Number of calves born, number of calves weaned, and cumulative weaning weight as measures of lifetime production for Hereford cows
}

G. E. Martinez

University of Nebraska-Lincoln

R. M. Koch

University of Nebraska-Lincoln

L. V. Cundiff

USDA-ARS, Roman L. Hruska U.S. Meat Animal Research Center

K. E. Gregory

USDA-ARS, Roman L. Hruska U.S. Meat Animal Research Center

L. Dale Van Vleck

University of Nebraska-Lincoln, dvan-vleck1@unl.edu

Follow this and additional works at: https://digitalcommons.unl.edu/animalscifacpub

Part of the Animal Sciences Commons

Martinez, G. E.; Koch, R. M.; Cundiff, L. V.; Gregory, K. E.; and Van Vleck, L. Dale, "Number of calves born, number of calves weaned, and cumulative weaning weight as measures of lifetime production for Hereford cows" (2004). Faculty Papers and Publications in Animal Science. 207.

https://digitalcommons.unl.edu/animalscifacpub/207

This Article is brought to you for free and open access by the Animal Science Department at DigitalCommons@University of Nebraska - Lincoln. It has been accepted for inclusion in Faculty Papers and Publications in Animal Science by an authorized administrator of DigitalCommons@University of Nebraska - Lincoln. 


\title{
Number of calves born, number of calves weaned, and cumulative weaning weight as measures of lifetime production for Hereford cows ${ }^{1}$
}

\author{
G. E. Martinez*2, R. M. Koch*, L. V. Cundiff $\dagger$, K. E. Gregory $\dagger$, and L. D. Van Vleck $\dagger \star^{3}$ \\ *Department of Animal Science, University of Nebraska, Lincoln 68583-0908; and ARS, USDA, Roman L. \\ Hruska U.S. Meat Animal Research Center, †Clay Center, NE 68933 and $\ddagger$ Lincoln, NE 68583-0908
}

\begin{abstract}
Genetic parameters for lifetime production for cows with the opportunity to produce from 2 through $7 \mathrm{yr}$ of age, as measured by the number of calves born (NB2, ..., NB7), the number of calves weaned (NW2, .., NW7), and cumulative weaning weight (CW2 , .., CW7), were estimated using data from 3,064 Hereford cows from a selection experiment with a control line (CTL) and three lines selected for weaning weight (WWL), yearling weight (YWL), and an index of yearling weight and muscle score (IXL). Weaning weights were adjusted to $200 \mathrm{~d}$ of age and for sex and age of dam. Estimates of heritability and genetic and environmental correlations were obtained by restricted maximum likelihood with bivariate animal models, with year of birth of the cow as a fixed effect and direct genetic and residual as random effects. Genetic trends were estimated by regressing means of estimated breeding values by year of birth and line on birth year. Estimates of heritability (SE) for opportunity groups of 2 to $7 \mathrm{yr}$ of age ranged from $0.08(0.03)$ to $0.16(0.05)$ for NB; from $0.05(0.02)$ to $0.16(0.05)$ for NW; and from $0.06(0.02)$ to $0.16(0.05)$ for CW. Estimates of genetic correlations (SE) among NB traits ranged from 0.60
\end{abstract}

(0.14) to 1.00 (0.00), and estimates of environmental correlations (SE) ranged from $0.67(0.02)$ to $0.99(0.00)$. For NW, estimates of genetic and environmental correlations ranged from $0.98(0.11)$ to $1.00(0.00)$ and from 0.65 (0.02) to 0.99 (0.00), respectively. Estimates of genetic correlations (SE) among $\mathrm{CW}$ traits ranged from $0.94(0.08)$ to 1.00 (0.00). Estimates of environmental correlations (SE) ranged from $0.66(0.02)$ to $0.99(0.00)$. Estimates of genetic correlations for NB2 with all definitions of NW ranged from 0.47 (0.18) to $0.71(0.12)$, and with all definitions of $\mathrm{CW}$ ranged from $0.55(0.16)$ to $0.80(0.11)$. Estimates of genetic correlations between NW2 and all definitions for CW ranged from $0.95(0.02)$ to 0.99 (0.06). Estimates of annual genetic (SE) change were negligible for NB2, NB6, NW2, and NW6 for all lines. Estimates of annual genetic (SE) change for CW2 were $0.85(0.11), 0.79(0.14), 0.51(0.10)$, and $0.52(0.18)$ $\mathrm{kg} / \mathrm{yr}$, and for CW6 were 5.01 (1.25), 2.64 (1.75), 3.67 (1.16), and 3.33 (2.37) kg/yr for WWL, YWL, IXL, and CTL, respectively. Selection for lifetime production as measured by NB, NW, or CW could be effective but would be relatively slow due to low estimates of heritability and to increased generation intervals.

Key Words: Beef Cattle, Longevity, Selection

(C2004 American Society of Animal Science. All rights reserved.

J. Anim. Sci. 2004. 82:1903-1911

\section{Introduction}

Lifetime production is an important measure of efficiency of beef production and is a function of fertility, maternal ability, and survival of the cow and her offspring. Cows with a long productive lifetime will be

\footnotetext{
${ }^{1}$ Published as paper No. 14255, Journal Ser., Nebraska Agric. Res. Div. Univ. of Nebraska, Lincoln 68583-0908.

${ }^{2}$ Current address: Instituto de Producción Animal, Facultad de Agronomia, Universidad Central de Venezuela, Apartado Postal 4579, Maracay 2101, Aragua, Venezuela.

${ }^{3}$ Correspondence: A218 Animal Science (phone: 402-472-6010; fax: 402-472-6362; e-mail: lvanvleck@unlnotes.unl.edu).

Received September 10, 2003.

Accepted April 12, 2004.
}

genetically superior for longevity and reproductive performance (Lasley, 1978). Dickerson (1970) stated that the cost of animal products depends primarily on efficiency of 1) female productivity, 2) reproduction, and $3)$ growth of the young.

The ability of cows to have a long productive life is important for commercial beef producers because a longer productive life means lower costs for rearing replacements, fewer young cows, and thus more and heavier calves available for sale (Rendel and Robertson, 1950). For purebred cattle breeders, increased lifetime production would permit greater selection intensity for other important traits. The weight of weaned calves per initial replacement female accumulated over a lifetime is a measure of the cow's contribution to the genotype of its calves for growth, its fertility (pregnancy 
and calving rate), its maternal ability (weaning rate), milking capacity (maternal weaning weight), and its survival (ability of the cow to delay culling or death), and has been proposed as a comprehensive measure of lifetime production (Tanida et al., 1988; Nuñez-Dominguez et al., 1991).

A previous study (Martinez et al., 2004) on six measures of length of productive life and three measures of lifetime production by $6 \mathrm{yr}$ after first calving, reported high genetic and environmental correlations among the three measures of lifetime production.

The objectives of this study were 1) to estimate genetic parameters for three measures of lifetime production conditional on the opportunity to produce 2 through $7 \mathrm{yr}$ of age, and 2) to estimate genetic and environmental trends for these measures of lifetime production for a control and three selected lines of Hereford cows.

\section{Materials and Methods}

\section{The Project}

Data were from the Nebraska Agric. Exp. Stn. Project 40-002 entitled "Effect of selection for weaning weight, yearling weight, and muscling in beef cattle," in cooperation with the Roman L. Hruska U.S. Meat Animal Research Center (USMARC) (Koch et al., 1974a,b; 1994). Data used were from animals born from 1964 through 1980.

\section{The Population}

The three selection lines were established in 1960 by randomly allocating 325 cows from 14 Hereford herds to the weaning weight line (WWL), the yearling weight line (YWL), and the index line based on yearling weight and muscle score (IXL). The 42 foundation sires used from 1957 to 1963 were from 11 of the same 14 herds as the cows and from two other herds (Koch et al., 1974a,b; 1994).

The cattle were at Fort Robinson Beef Cattle Research Station, Crawford, NE, until 1971, when they were moved to USMARC, near Clay Center, NE. The projected herd size of 150 breeding females per line was reached by 1964 and maintained until the end of the experiment. Approximately 225 foundation cows and other cows from the three selection lines that had been replaced were artificially inseminated with semen from seven of the foundation sires from 1968 through 1971 to provide the basis for a control line (CTL). In 1971, the CTL was established from 20 representative sons and heifer calves from matings with the 225 cows (Koch et al., 1974a,b; 1994).

Bulls were selected at $2 \mathrm{yr}$ of age. Through 1970, two bulls were chosen from each year of birth and used to sire calves when 3, 4, and 5 yr old. After 1970, three 2 -yr-old bulls were selected each year to be used for 2 yr (i.e., they sired calves when 3 and 4 yr of age). Bulls were removed from service early only because of breed- ing unsoundness. To minimize inbreeding no more than two sons of a given sire or dam were selected (Koch et al., 1974a,b; 1994). Heifers born in 1964 and later were bred to calve at $2 \mathrm{yr}$ of age. All heifers were exposed to bulls. Selection was practiced only among those that were pregnant. From 1964 through 1970, the top 25 heifers from each line were selected based on their line data. From 1971 through 1973, the top 35 heifers were selected. From 1974 through 1984, all pregnant heifers were kept in the herd. No heifers that were pregnant were eliminated from the analysis. Cows were removed without regard to progeny performance based on the following criteria (Koch et al., 1974a,b; 1994): 1) not pregnant at weaning time; 2) serious unsoundness, which was rare (e.g., cancer eye, chronic bloat, bad mouth); 3) failure to raise a live calf for two consecutive years; and 4) older cows were removed if cows needed to be culled to maintain herd size.

For each breeding season, mating sires were randomly assigned to females within each age and line, except that half-sib or more closely related matings were avoided.

These criteria were the basis of the management protocol to maintain herd size, although exceptions were occasionally made if more cows were needed (e.g., nonpregnant cows would be carried over to maintain herd size). The number of cows in these categories was not counted.

All lines were maintained as one herd except during the 60-d breeding season. The herd calved only in the spring, mostly in March and April. Cows were palpated for pregnancy once at weaning. Heifers were palpated at about 18 mo of age. Calves were weaned together each year when the average age was about $200 \mathrm{~d}$ (Koch et al., 1974a,b; 1994).

\section{Selection Objectives in the Original Project}

Selection in WWL was based on weight adjusted to $200 \mathrm{~d}$ of age. Selection in YWL was based on weight at $452 \mathrm{~d}$ (approximately 15 mo of age) for bulls and at 550 $\mathrm{d}$ (approximately $18 \mathrm{mo}$ of age) for heifers. Selection in IXL was based on an index giving equal emphasis to muscle score and yearling weight when both were expressed in standard measure. Selection of heifers in IXL from birth years 1960 through 1965 was based on yearling weight alone. Originally, only bulls were evaluated for muscle score, but beginning in the 1966 birth year, heifers were also evaluated for muscle score and were also selected for an index of muscle score and yearling weight until the end of the experiment (Koch et al., 1974a,b; 1994). Selection continued through matings to produce the 1982 calf crop.

\section{Analysis of Measures of Lifetime Production}

Records qualified for analysis only if the cow were available for breeding as a yearling. Thus, lifetime production traits were defined only for heifers that entered 
Table 1. Summary of statistics unadjusted for model effects for number of calves born, number of calves weaned, and total weight of calves weaned for different opportunity groups $^{\mathrm{a}}$

\begin{tabular}{|c|c|c|c|c|c|c|}
\hline Item & No. & Mean & $\mathrm{SD}$ & $\mathrm{CV}, \%$ & Minimum & Maximum \\
\hline \multicolumn{7}{|c|}{ Calves born } \\
\hline NB2 & 3,064 & 0.72 & 0.45 & 63 & 0 & 1 \\
\hline NB3 & 2,842 & 1.19 & 0.84 & 71 & 0 & 2 \\
\hline NB4 & 2,640 & 1.57 & 1.25 & 79 & 0 & 3 \\
\hline NB5 & 2,411 & 1.87 & 1.64 & 88 & 0 & 4 \\
\hline NB6 & 2,195 & 2.11 & 2.00 & 95 & 0 & 5 \\
\hline NB7 & 1,978 & 2.38 & 2.37 & 100 & 0 & 6 \\
\hline \multicolumn{7}{|c|}{ Calves weaned } \\
\hline NW2 & 3,064 & 0.55 & 0.50 & 91 & 0 & 1 \\
\hline NW3 & 2,842 & 0.97 & 0.87 & 90 & 0 & 2 \\
\hline NW4 & 2,640 & 1.31 & 1.25 & 96 & 0 & 3 \\
\hline NW5 & 2,411 & 1.59 & 1.62 & 102 & 0 & 4 \\
\hline NW6 & 2,195 & 1.81 & 1.94 & 107 & 0 & 5 \\
\hline NW7 & 1,978 & 2.06 & 2.27 & 110 & 0 & 6 \\
\hline \multicolumn{7}{|c|}{$\begin{array}{l}\text { Total weaning weight } \\
\text { of calves }\end{array}$} \\
\hline CW2 & 3,064 & 107 & 99 & 93 & 0 & 265 \\
\hline CW3 & 2,842 & 192 & 176 & 92 & 0 & 527 \\
\hline CW4 & 2,640 & 261 & 253 & 97 & 0 & 779 \\
\hline CW5 & 2,411 & 315 & 325 & 103 & 0 & 1,026 \\
\hline CW6 & 2,195 & 357 & 388 & 109 & 0 & 1,209 \\
\hline CW7 & 1,978 & 408 & 457 & 112 & 0 & 1,414 \\
\hline
\end{tabular}

${ }^{a} \mathrm{NB} 2$ to NB7 represent total number of calves born by 2 to $7 \mathrm{yr}$ of age for Opportunity Groups 2 to 7 ; NW2 to NW7 represent total number of calves weaned by 2 to $7 \mathrm{yr}$ of age for Opportunity Groups 2 to 7; CW2 to CW7 represent total weaning weight (kg) of calves weaned by 2 to $7 \mathrm{yr}$ of age for Opportunity Groups 2 to 7.

the breeding program as yearlings. For each of the three measures of lifetime production, six opportunity groups were defined, based on whether the cow was born early enough in the experiment to have the opportunity to live to calve at $2,3,4,5,6$, and $7 \mathrm{y}$ of age.

The three general measures of lifetime production (LP) were defined as 1) total number of calves born (NB) by 2 (NB2), 3 (NB3), 4 (NB4), 5 (NB5), 6 (NB6), and $7 \mathrm{yr}$ of age (NB7); 2) total number of calves weaned (NW) by 2 (NW2), 3 (NW3), 4 (NW4), 5 (NW5), 6 (NW6), and $7 \mathrm{yr}$ of age (NW7); and 3) total weaning weight in $\mathrm{kg}$ of all calves $(\mathbf{C W}$; adjusted to $200 \mathrm{~d}$ of age and for sex and age of dam) by 2 (CW2), 3 (CW3), 4 (CW4), 5 (CW5), 6 (CW6), and $7 \mathrm{yr}$ of age (CW7).

These definitions imply part-whole correlations within a type of measure. Cows that were not pregnant in any year were given values of zero for NB, NW, and $\mathrm{CW}$, as were pregnant cows that were kept in the herd after weaning but were culled before calving.

Number of calves born did not include abortions at any stage of pregnancy and did not include twins, and therefore is equivalent to total single calves born alive or dead. Records of a cow that had twins were deleted from all analyses.

Genetic parameters were estimated using two-trait animal models within type of measure (e.g., NB2 with NB3, NB4, NB5, NB6, and NB7) and similarly for NW and CW. In addition, two-trait animal models were used for analyses of NB2 with all opportunity groups for NW and $\mathrm{CW}$ and of NW2 with all opportunity groups for CW.
For all traits, the model included birth year of the cow as a fixed effect and random direct genetic effect. The two-trait animal model was as follows:

$$
\left[\begin{array}{l}
\mathrm{y}_{1} \\
\mathrm{y}_{2}
\end{array}\right]=\left[\begin{array}{cc}
\mathrm{X}_{1} & 0 \\
0 & \mathrm{X}_{2}
\end{array}\right]\left[\begin{array}{l}
\mathrm{b}_{1} \\
\mathrm{~b}_{2}
\end{array}\right]+\left[\begin{array}{cc}
\mathrm{Z}_{1} & 0 \\
0 & \mathrm{Z}_{2}
\end{array}\right]\left[\begin{array}{l}
\mathrm{u}_{1} \\
\mathrm{u}_{2}
\end{array}\right]+\left[\begin{array}{l}
\mathrm{e}_{1} \\
\mathrm{e}_{2}
\end{array}\right]
$$

where $\mathrm{y}_{1}=$ an $\mathrm{n}_{1} \times 1$ vector of observations for Trait 1 ; $\mathrm{y}_{2}=$ an $\mathrm{n}_{2} \times 1$ vector of observations for Trait $2 ; \mathrm{b}_{1}=$ vector of fixed effects for Trait $1 ; b_{2}=$ vector of fixed effects for Trait $2 ; \mathrm{u}_{1}=$ vector of random animal direct genetic effects for Trait $1 ; \mathrm{u}_{2}=$ vector of random animal direct genetic effects for Trait $2 ; \mathrm{e}_{1}=$ an $\mathrm{n}_{1} \times 1$ vector of random residual effects for Trait $1 ; \mathrm{e}_{2}=$ an $\mathrm{n}_{2} \times 1$ vector of random residual effects for Trait 2 ; and $\mathrm{X}, \mathrm{Z}=$ known incidence matrices relating the observations to fixed and random effects, respectively, with $\mathrm{u}_{1}, \mathrm{u}_{2}, \mathrm{Z}_{1}$, and $\mathrm{Z}_{2}$ augmented for relatives without records.

The first and second moments of the model are assumed to be:

$$
\mathrm{E}\left[\begin{array}{c}
\mathrm{y}_{1} \\
\mathrm{y}_{2} \\
\mathrm{u}_{1} \\
\mathrm{u}_{2} \\
\mathrm{e}_{1} \\
\mathrm{e}_{2}
\end{array}\right]=\left[\begin{array}{c}
\mathrm{X}_{1} \mathrm{~b}_{1} \\
\mathrm{X}_{2} \mathrm{~b}_{2} \\
0 \\
0 \\
0 \\
0
\end{array}\right] \text { and } \operatorname{Var}\left[\begin{array}{c}
\mathrm{u}_{1} \\
\mathrm{u}_{2} \\
\mathrm{e}_{1} \\
\mathrm{e}_{2}
\end{array}\right]=\left[\begin{array}{cc}
\mathrm{G}_{0} \otimes \mathrm{A} & 0 \\
0 & \mathrm{R}_{\mathrm{e}}
\end{array}\right]
$$

where A = Wright's numerator relationship matrix and 
Table 2. Estimates (standard errors) of heritability and genetic and environmental correlations from two-trait analyses for lifetime production measured as number of calves born for several opportunity groups (e.g., NB2 = total number of calves born by $2 \mathrm{yr}$ of age)

\begin{tabular}{lccccccc}
\hline \hline Trait 1 & Trait 2 & $\sigma_{\mathrm{p} 1}^{2}$ & $\sigma_{\mathrm{p} 2}^{2}$ & $\mathrm{~h}_{1}^{2}$ & $\mathrm{~h}_{2}^{2}$ & $\mathrm{r}_{\mathrm{g}}$ & $\mathrm{r}_{\mathrm{e}}$ \\
\hline NB2 & NB3 & 0.19 & 0.68 & $0.08 \pm 0.03$ & $0.10 \pm 0.04$ & $0.83 \pm 0.06$ & $0.87 \pm 0.01$ \\
& NB4 & 0.19 & 1.51 & $0.08 \pm 0.03$ & $0.11 \pm 0.04$ & $0.69 \pm 0.10$ & $0.78 \pm 0.01$ \\
& NB5 & 0.19 & 2.59 & $0.08 \pm 0.03$ & $0.12 \pm 0.04$ & $0.64 \pm 0.14$ & $0.73 \pm 0.01$ \\
& NB6 & 0.19 & 3.81 & $0.08 \pm 0.03$ & $0.14 \pm 0.04$ & $0.63 \pm 0.14$ & $0.69 \pm 0.02$ \\
& NB7 & 0.19 & 5.26 & $0.08 \pm 0.03$ & $0.16 \pm 0.05$ & $0.60 \pm 0.14$ & $0.67 \pm 0.02$ \\
NB3 & NB4 & 0.69 & 1.54 & $0.10 \pm 0.04$ & $0.11 \pm 0.04$ & $0.99 \pm 0.01$ & $0.96 \pm 0.01$ \\
& NB5 & 0.69 & 2.64 & $0.10 \pm 0.04$ & $0.12 \pm 0.04$ & $0.96 \pm 0.02$ & $0.92 \pm 0.01$ \\
& NB6 & 0.69 & 3.85 & $0.10 \pm 0.04$ & $0.14 \pm 0.04$ & $0.95 \pm 0.03$ & $0.89 \pm 0.01$ \\
& NB7 & 0.69 & 5.28 & $0.10 \pm 0.04$ & $0.16 \pm 0.05$ & $0.94 \pm 0.03$ & $0.86 \pm 0.01$ \\
NB4 & NB5 & 1.54 & 2.65 & $0.11 \pm 0.04$ & $0.12 \pm 0.04$ & $1.00 \pm 0.00$ & $0.98 \pm 0.01$ \\
& NB6 & 1.54 & 3.91 & $0.11 \pm 0.04$ & $0.14 \pm 0.04$ & $1.00 \pm 0.01$ & $0.95 \pm 0.01$ \\
& NB7 & 1.54 & 5.32 & $0.11 \pm 0.04$ & $0.16 \pm 0.05$ & $1.00 \pm 0.00$ & $0.94 \pm 0.01$ \\
NB5 & NB6 & 2.68 & 3.98 & $0.12 \pm 0.04$ & $0.14 \pm 0.04$ & $1.00 \pm 0.00$ & $0.99 \pm 0.00$ \\
& NB7 & 2.64 & 5.34 & $0.12 \pm 0.04$ & $0.15 \pm 0.05$ & $1.00 \pm 0.00$ & $0.97 \pm 0.00$ \\
NB6 & NB7 & 3.97 & 5.34 & $0.14 \pm 0.04$ & $0.16 \pm 0.05$ & $1.00 \pm 0.00$ & $0.99 \pm 0.00$ \\
\hline
\end{tabular}

$\sigma_{\mathrm{p} 1}^{2}=$ estimate of phenotypic variance for trait $1 ; \sigma_{\mathrm{p} 2}^{2}=$ estimate of phenotypic variance for trait $2 ; \mathrm{h}_{1}^{2}=$ estimate of heritability for trait $1 ; \mathrm{h}_{2}^{2}=$ estimate of heritability for trait $2 ; \mathrm{r}_{\mathrm{g}}=$ estimate of genetic correlation; $r_{e}=$ estimate of environmental correlation.

$$
\mathrm{G}_{0}=\left[\begin{array}{cc}
\sigma_{\mathrm{u} 1}^{2} & \sigma_{\mathrm{u} 1 \mathrm{u} 2} \\
\sigma_{\mathrm{u} 1 \mathrm{u} 2} & \sigma_{\mathrm{u} 2}^{2}
\end{array}\right]
$$

$\sigma_{\mathrm{u} 1}^{2}=$ additive genetic variance for Trait $1 ; \sigma_{\mathrm{u} 2}^{2}=$ additive genetic variance for Trait $2 ; \sigma_{\mathrm{u} 1 \mathrm{u} 2}=$ additive genetic covariance between Traits 1 and 2 :

$$
\mathrm{R}_{\mathrm{e}}=\left[\begin{array}{ccc}
\sigma_{\mathrm{e} 1}^{2} \mathrm{I}_{1} & 0 & 0 \\
0 & \mathrm{R}_{0} \otimes \mathrm{I}_{2} & 0 \\
0 & 0 & \sigma_{\mathrm{e} 2}^{2} \mathrm{I}_{3}
\end{array}\right], \mathbf{R}_{0}=\left[\begin{array}{cc}
\sigma_{\mathrm{e} 1}^{2} & \sigma_{\mathrm{e} 1 \mathrm{e} 2} \\
\sigma_{\mathrm{e} 1 \mathrm{e} 2} & \sigma_{\mathrm{e} 2}^{2}
\end{array}\right]
$$

$\sigma_{\mathrm{e} 1}^{2}=$ residual variance for Trait $1 ; \sigma_{\mathrm{e} 2}^{2}=$ residual variance for Trait $2 ; \sigma_{\mathrm{e} 1 \mathrm{e} 2}=$ residual covariance between Traits 1 and $2 ; \mathrm{I}_{1}=$ an identity matrix with order number of animals with records only for Trait $1 ; I_{2}=$ an identity matrix with order number of animals with records for both traits; and $\mathrm{I}_{3}=$ an identity matrix with order number of animals with records only for Trait 2 .

For pairwise analyses with no missing values (e.g., NB2 with NW2, NB2 with CW2, and NW2 with CW2 $\left.\left[\mathrm{n}_{1}=\mathrm{n}_{2}\right]\right), \mathrm{I}_{1}$ and $\mathrm{I}_{3}$ will collapse into $\mathrm{I}_{2}$ (i.e., $\mathrm{R}_{\mathrm{e}}=\mathrm{R}_{0} \otimes \mathrm{I}_{2}$ ).

Estimates of genetic parameters were obtained using a multiple-trait, derivative-free algorithm to obtain restricted maximum likelihood estimates with MTDFREML (Boldman et al., 1995). Starting values for the estimates of (co)variance components were from the literature (Morris et al., 1987, 1993; Tanida et al., 1988). The simplex algorithm was stopped when the variance of the function values (i.e., $-2 \log \mathrm{L}$ with $\mathrm{L}=$ likelihood given y) in the simplex was less than $1 \times$ $10^{-6}$. Once that convergence criterion was reached, fresh restarts from those estimates were continued until -2logL differed less than $1 \times 10^{-2}$ between successive restarts. The (co)variance components attained from the last restart were used for estimating breeding values.

Standard errors for two-trait analyses with the same number of observations were obtained directly from MTDFREML using the average information matrix. The MTDFREML program does not calculate standard errors for estimates of genetic parameters for multipletrait analyses when there are missing observations. Therefore, an AIREML algorithm (Kachman, 2001) was used with MATVEC (Wang et al., 2002) to obtain the average information matrix at convergence. Standard errors were estimated using the "delta method" and the average information matrix at convergence (Searle et al., 1992).

Estimates of genetic change were obtained by regressing the average of estimated breeding values by year of birth for each line on birth year. Estimates of environmental change were estimated by regressing the solutions for year of birth on birth year. Estimates of genetic and environmental change were estimated only for NB2, NB6, NW2, NW6, CW2, and CW6.

\section{Results and Discussion}

Table 1 summarizes descriptive statistics for the measures of NB, NW, and CW for different opportunity groups, respectively. Phenotypic means (SD) for NB ranged from $0.72(0.45)$ for NB2 to 2.38 (2.37) calves for NB7. These means are similar to some reported in the literature (Schons et al., 1985; Morris et al., 1987; Arthur et al., 1993). Phenotypic means for NW ranged from 0.55 (0.50) for NW2 to 2.06 (2.27) calves weaned for NW7, which are comparable to some previously reported values (Tanida et al., 1988; Arthur et al., 1993; Davis et al., 1994). Phenotypic means for CW ranged from 107 (99) for CW2 to 408 (457) $\mathrm{kg}$ for CW7. These 
Table 3. Estimates (standard errors) of heritability and genetic and environmental correlations from two-trait analyses for lifetime production measured as number of calves weaned for several opportunity groups (e.g., NW2 = total number of calves weaned by 2 yr of age)

\begin{tabular}{lccccccc}
\hline \hline Trait 1 & Trait 2 & $\sigma_{\mathrm{p} 1}^{2}$ & $\sigma_{\mathrm{p} 2}^{2}$ & $\mathrm{~h}_{1}^{2}$ & $\mathrm{~h}_{2}^{2}$ & $\mathrm{r}_{\mathrm{g}}$ & $\mathrm{r}_{\mathrm{e}}$ \\
\hline NW2 & NW3 & 0.23 & 0.73 & $0.05 \pm 0.02$ & $0.09 \pm 0.03$ & $0.99 \pm 0.10$ & $0.95 \pm 0.01$ \\
& NW4 & 0.24 & 1.53 & $0.05 \pm 0.02$ & $0.11 \pm 0.03$ & $0.99 \pm 0.11$ & $0.78 \pm 0.01$ \\
& NW5 & 0.23 & 2.58 & $0.05 \pm 0.02$ & $0.13 \pm 0.04$ & $0.99 \pm 0.12$ & $0.72 \pm 0.01$ \\
& NW6 & 0.23 & 3.71 & $0.05 \pm 0.02$ & $0.15 \pm 0.04$ & $0.98 \pm 0.11$ & $0.68 \pm 0.02$ \\
& NW7 & 0.23 & 5.11 & $0.05 \pm 0.02$ & $0.16 \pm 0.05$ & $0.98 \pm 0.11$ & $0.65 \pm 0.02$ \\
NW3 & NW4 & 0.74 & 1.54 & $0.09 \pm 0.03$ & $0.10 \pm 0.03$ & $1.00 \pm 0.01$ & $0.96 \pm 0.00$ \\
& NW5 & 0.74 & 2.59 & $0.09 \pm 0.03$ & $0.13 \pm 0.04$ & $1.00 \pm 0.01$ & $0.91 \pm 0.01$ \\
& NW6 & 0.74 & 3.74 & $0.09 \pm 0.03$ & $0.16 \pm 0.05$ & $0.99 \pm 0.01$ & $0.88 \pm 0.01$ \\
& NW7 & 0.74 & 5.12 & $0.09 \pm 0.03$ & $0.16 \pm 0.05$ & $0.99 \pm 0.01$ & $0.84 \pm 0.02$ \\
NW4 & NW5 & 1.54 & 2.60 & $0.11 \pm 0.03$ & $0.12 \pm 0.04$ & $1.00 \pm 0.01$ & $0.98 \pm 0.00$ \\
& NW6 & 1.58 & 3.83 & $0.11 \pm 0.03$ & $0.15 \pm 0.04$ & $1.00 \pm 0.01$ & $0.95 \pm 0.01$ \\
& NW7 & 1.58 & 5.26 & $0.11 \pm 0.03$ & $0.16 \pm 0.05$ & $1.00 \pm 0.01$ & $0.92 \pm 0.01$ \\
NW5 & NW6 & 2.64 & 3.83 & $0.13 \pm 0.04$ & $0.15 \pm 0.04$ & $1.00 \pm 0.00$ & $0.99 \pm 0.00$ \\
& NW7 & 2.64 & 5.23 & $0.13 \pm 0.04$ & $0.16 \pm 0.05$ & $1.00 \pm 0.00$ & $0.97 \pm 0.00$ \\
NW6 & NW7 & 3.90 & 5.24 & $0.15 \pm 0.05$ & $0.16 \pm 0.05$ & $1.00 \pm 0.00$ & $0.99 \pm 0.00$ \\
\hline
\end{tabular}

$\sigma_{\mathrm{p} 1}^{2}=$ estimate of phenotypic variance for trait $1 ; \sigma_{\mathrm{p} 2}^{2}=$ estimate of phenotypic variance for trait $2 ; \mathrm{h}_{1}^{2}=$ estimate of heritability for trait $1 ; \mathrm{h}_{2}^{2}=$ estimate of heritability for trait $2 ; \mathrm{r}_{\mathrm{g}}=$ estimate of genetic correlation; $r_{e}=$ estimate of environmental correlation.

means are similar to some reports in the literature (Tanida et al., 1988; Arthur et al., 1993; Davis et al., 1994). In general, all three measures of lifetime production were smaller than those reported by Bailey (1991) and Cundiff et al. (1992).

\section{Estimates of Genetic Parameters}

Table 2 summarizes estimates of heritability and genetic and environmental correlations for NB2 to NB7. Estimates of heritability for NB were low, ranging from
0.08 for NB2 to 0.16 for NB7. Estimates of heritability tended to increase with added length of the opportunity group with averages of $0.08,0.10,0.11,0.12,0.14$, and 0.16 for NB2, NB3, NB4, NB5, NB6, and NB7, respectively. The increase in estimates of heritability may be due to increased opportunity for genetic differences to be expressed. The estimates of heritability are similar to previous reports. Morris et al. (1987) reported an estimate of heritability for number born (single calves alive or dead) of 0.05 (0.05) for crossbred cows. Morris et al. (1993) reported an estimate of heritability of 0.06

Table 4. Estimates (standard errors) of heritability and genetic and environmental correlations from two-trait analyses for lifetime production measured as cumulative weaning weight $(\mathrm{kg})$ for several opportunity groups (e.g., CW2 = total weaning weight in $\mathrm{kg}$ of all calves by 2 yr of age)

\begin{tabular}{lcrrcccc}
\hline \hline Trait 1 & Trait 2 & \multicolumn{1}{c}{$\sigma_{\mathrm{p} 1}^{2}$} & \multicolumn{1}{c}{$\sigma_{\mathrm{p} 2}^{2}$} & $\mathrm{~h}_{1}^{2}$ & $\mathrm{~h}_{2}^{2}$ & $\mathrm{r}_{\mathrm{g}}$ & $\mathrm{r}_{\mathrm{e}}$ \\
\hline CW2 & CW3 & 9,244 & 29,406 & $0.06 \pm 0.02$ & $0.09 \pm 0.03$ & $0.99 \pm 0.06$ & $0.87 \pm 0.01$ \\
& CW4 & 9,270 & 61,981 & $0.06 \pm 0.02$ & $0.12 \pm 0.04$ & $0.98 \pm 0.06$ & $0.78 \pm 0.01$ \\
& CW5 & 9,257 & 104,109 & $0.06 \pm 0.02$ & $0.13 \pm 0.04$ & $0.96 \pm 0.06$ & $0.73 \pm 0.02$ \\
& CW6 & 9,260 & 149,405 & $0.06 \pm 0.02$ & $0.15 \pm 0.04$ & $0.94 \pm 0.08$ & $0.69 \pm 0.02$ \\
& CW7 & 9,251 & 206,009 & $0.06 \pm 0.02$ & $0.16 \pm 0.05$ & $0.96 \pm 0.06$ & $0.66 \pm 0.02$ \\
CW3 & CW4 & 30,252 & 63,254 & $0.10 \pm 0.03$ & $0.11 \pm 0.04$ & $1.00 \pm 0.01$ & $0.96 \pm 0.00$ \\
& CW5 & 29,816 & 104,663 & $0.10 \pm 0.03$ & $0.12 \pm 0.04$ & $0.99 \pm 0.01$ & $0.92 \pm 0.01$ \\
& CW6 & 29,871 & 150,919 & $0.10 \pm 0.03$ & $0.14 \pm 0.04$ & $0.98 \pm 0.01$ & $0.88 \pm 0.01$ \\
& CW7 & 29,951 & 208,306 & $0.10 \pm 0.03$ & $0.16 \pm 0.05$ & $0.97 \pm 0.01$ & $0.85 \pm 0.02$ \\
CW4 & CW5 & 63,746 & 106,648 & $0.11 \pm 0.04$ & $0.12 \pm 0.04$ & $1.00 \pm 0.00$ & $0.98 \pm 0.01$ \\
& CW6 & 63,994 & 154,311 & $0.11 \pm 0.04$ & $0.14 \pm 0.04$ & $1.00 \pm 0.01$ & $0.95 \pm 0.01$ \\
& CW7 & 64,004 & 211,904 & $0.14 \pm 0.04$ & $0.16 \pm 0.05$ & $1.00 \pm 0.01$ & $0.92 \pm 0.01$ \\
CW5 & CW6 & 106,884 & 154,485 & $0.12 \pm 0.04$ & $0.14 \pm 0.04$ & $1.00 \pm 0.00$ & $0.98 \pm 0.00$ \\
& CW7 & 106,747 & 210,147 & $0.12 \pm 0.04$ & $0.16 \pm 0.05$ & $1.00 \pm 0.00$ & $0.96 \pm 0.00$ \\
CW6 & CW7 & 152,674 & 204,482 & $0.14 \pm 0.04$ & $0.15 \pm 0.05$ & $1.00 \pm 0.00$ & $0.99 \pm 0.00$ \\
\hline
\end{tabular}

$\sigma_{\mathrm{p} 1}^{2}=$ estimate of phenotypic variance for trait $1 ; \sigma_{\mathrm{p} 2}^{2}=$ estimate of phenotypic variance for trait $2 ; \mathrm{h}_{1}^{2}=$ estimate of heritability for trait $1 ; \mathrm{h}_{2}^{2}=$ estimate of heritability for trait $2 ; \mathrm{r}_{\mathrm{g}}=$ estimate of genetic correlation; $\mathrm{r}_{\mathrm{e}}=$ estimate of environmental correlation. 
Table 5. Estimates (standard errors) of heritability and genetic and environmental correlations from two-trait analyses of NB2 with NW2 through NW7 ${ }^{a}$

\begin{tabular}{lccccccc}
\hline \hline Trait 1 & Trait 2 & $\sigma_{\mathrm{p} 1}^{2}$ & $\sigma_{\mathrm{p} 2}^{2}$ & $\mathrm{~h}_{1}^{2}$ & $\mathrm{~h}_{2}^{2}$ & $\mathrm{r}_{\mathrm{g}}$ & $\mathrm{r}_{\mathrm{e}}$ \\
\hline NB2 & NW2 & 0.19 & 0.23 & $0.08 \pm 0.03$ & $0.05 \pm 0.02$ & $0.71 \pm 0.12$ & $0.68 \pm 0.01$ \\
& NW3 & 0.19 & 0.73 & $0.08 \pm 0.03$ & $0.09 \pm 0.03$ & $0.61 \pm 0.12$ & $0.68 \pm 0.01$ \\
& NW4 & 0.19 & 1.53 & $0.08 \pm 0.03$ & $0.11 \pm 0.04$ & $0.47 \pm 0.18$ & $0.65 \pm 0.01$ \\
& NW5 & 0.19 & 2.54 & $0.08 \pm 0.03$ & $0.13 \pm 0.04$ & $0.52 \pm 0.14$ & $0.63 \pm 0.02$ \\
& NW6 & 0.19 & 3.59 & $0.08 \pm 0.03$ & $0.15 \pm 0.04$ & $0.54 \pm 0.14$ & $0.61 \pm 0.02$ \\
& NW7 & 0.19 & 4.89 & $0.08 \pm 0.03$ & $0.16 \pm 0.05$ & $0.51 \pm 0.13$ & $0.60 \pm 0.02$
\end{tabular}

${ }^{\mathrm{a}} \mathrm{NB} 2$ = total number of calves born by $2 \mathrm{yr}$ of age; NW2 = total number of calves weaned by 2 yr of age; NW7 = total number of calves weaned by $7 \mathrm{yr}$ of age; $\sigma_{\mathrm{p} 1}^{2}=$ estimate of phenotypic variance for Trait 1 ; $\sigma_{\mathrm{p} 2}^{2}=$ estimate of phenotypic variance for Trait $2 ; \mathrm{h}_{1}^{2}=$ estimate of heritability for Trait $1 ; \mathrm{h}_{2}^{2}=$ estimate of heritability for Trait $2 ; \mathrm{r}_{\mathrm{g}}=$ estimate of genetic correlation; $\mathrm{r}_{\mathrm{e}}=$ estimate of environmental correlation.

(0.22) for Hereford cows, 0.11 (0.09) for crossbred cows, and $0.11(0.08)$ for combined data of Hereford and crossbred cows.

Estimates of genetic and environmental correlations were high, ranging from 0.60 to 1.00 and 0.67 to 0.99 , respectively. Estimates of genetic correlations for NB2 with NB3, NB4, NB5, NB6, and NB7 were $0.83,0.69$, $0.64,0.63$, and 0.60 , respectively. The pattern was similar for all other combinations of NB.

Estimates of environmental correlations were slightly larger than estimates of genetic correlations, but as with estimates of genetic correlations the estimate decreased with each added increment of one year for the opportunity group. Estimates of environmental correlations for NB2 with NB3, NB4, NB5, NB6, and NB7, were $0.87,0.78,0.73,0.69$, and 0.66 , respectively.

Table 3 summarizes estimates of heritability and genetic and environmental correlations for NW2 to NW7. Estimates of heritability for NW were low, ranging from 0.05 for NW2 to 0.16 for NW7. Estimates of heritability tended to increase with each increment in length for the opportunity group, with average estimates of 0.05 , $0.09,0.11,0.13,0.15$, and 0.16 for NW2, NW3, NW4, NW5, NW6, and NW7, respectively. Estimates of heritability were similar to those found in the literature. Morris et al. (1987) reported an estimate of heritability for number weaned of 0.02 (0.04) for crossbred cows. Tanida et al. (1988) reported an estimate of heritability of 0.16 (0.08) from daughter-dam regression, and 0.22 (0.08) from paternal half-sib analysis for Hereford cows, and 0.03 (0.14) from paternal half-sib analysis for Angus cows. Arthur and Makarechian (1992) indicated an estimate of heritability of 0.28 (0.14), and Arthur et al. (1994) reported an estimate of 0.24 (0.02) for Hereford cows. Morris et al. (1993) reported an estimate of heritability of $0.13(0.23)$ for Hereford cows, 0.03 (0.08) for crossbred cows, and $0.15(0.08)$ for the combined analysis of Hereford and crossbred cows.

Estimates of genetic and environmental correlations were high, ranging from 0.98 to 1.00 and from 0.65 to 0.99 , respectively. Estimates of genetic correlations for NW2 with NW3, NW4, NW5, NW6, and NW7 were 0.99, $0.99,0.99,0.98$, and 0.98 , respectively, with a similar pattern for the other combinations of NW. Estimates of environmental correlations decreased with increase in length of opportunity group for all analyses. Estimates of environmental correlations for NW2 with NW3, NW4, NW5, NW6, and NW7, were 0.95, 0.78, $0.72,0.68$, and 0.65 , respectively. No reports were found in the literature.

Table 4 summarizes estimates of heritability and genetic and environmental correlations for CW2 to CW7. Estimates of heritability for $\mathrm{CW}$ were low, ranging from 0.06 for CW2 to 0.16 for CW7. Estimates of heritability tended to increase with increased length of opportunity group with average estimates of $0.06,0.10,0.11,0.12$,

Table 6. Estimates (standard errors) of heritability and genetic and environmental correlations from two-trait analyses of NB2 with CW2 through CW7 ${ }^{a}$

\begin{tabular}{lccrcccc}
\hline \hline Trait 1 & Trait 2 & $\sigma_{\mathrm{p} 1}^{2}$ & \multicolumn{1}{c}{$\sigma_{\mathrm{p} 2}^{2}$} & $\mathrm{~h}_{1}^{2}$ & $\mathrm{~h}_{2}^{2}$ & $\mathrm{r}_{\mathrm{g}}$ & $\mathrm{r}_{\mathrm{e}}$ \\
\hline NB2 & CW2 & 0.19 & 9,236 & $0.08 \pm 0.03$ & $0.06 \pm 0.02$ & $0.80 \pm 0.11$ & $0.66 \pm 0.01$ \\
& CW3 & 0.19 & 29,473 & $0.08 \pm 0.03$ & $0.09 \pm 0.03$ & $0.68 \pm 0.12$ & $0.66 \pm 0.01$ \\
& CW4 & 0.19 & 61,819 & $0.08 \pm 0.03$ & $0.11 \pm 0.03$ & $0.55 \pm 0.16$ & $0.63 \pm 0.02$ \\
& CW5 & 0.19 & 102,075 & $0.08 \pm 0.03$ & $0.12 \pm 0.04$ & $0.60 \pm 0.13$ & $0.61 \pm 0.02$ \\
& CW6 & 0.19 & 143,624 & $0.08 \pm 0.03$ & $0.14 \pm 0.04$ & $0.63 \pm 0.13$ & $0.59 \pm 0.02$ \\
& CW7 & 0.19 & 196,374 & $0.08 \pm 0.03$ & $0.16 \pm 0.05$ & $0.60 \pm 0.14$ & $0.58 \pm 0.02$ \\
\hline
\end{tabular}

${ }^{\mathrm{a} N B 2}=$ total number of calves born by $2 \mathrm{yr}$ of age; CW2 = total weaning weight (kg) by 2 yr of age; CW7 = total weaning weight $(\mathrm{kg})$ by $7 \mathrm{yr}$ of age; $\sigma_{\mathrm{p} 1}^{2}=$ estimate of phenotypic variance for Trait $1 ; \sigma_{\mathrm{p} 2}^{2}=$ estimate of phenotypic variance for Trait $2 ; \mathrm{h}_{1}^{2}=$ estimate of heritability for Trait $1 ; \mathrm{h}_{2}^{2}=$ estimate of heritability for Trait $2 ; \mathrm{r}_{\mathrm{g}}=$ estimate of genetic correlation; $\mathrm{r}_{\mathrm{e}}=$ estimate of environmental correlation. 
Table 7. Estimates (standard errors) of heritability and genetic and environmental correlations from two-trait analyses of NW2 with CW2 through CW7

\begin{tabular}{lccrcccc}
\hline \hline Trait 1 & Trait 2 & $\sigma_{\mathrm{p} 1}^{2}$ & \multicolumn{1}{c}{$\sigma_{\mathrm{p} 2}^{2}$} & \multicolumn{1}{c}{$\mathrm{h}_{1}^{2}$} & $\mathrm{~h}_{2}^{2}$ & $\mathrm{r}_{\mathrm{g}}$ & $\mathrm{r}_{\mathrm{e}}$ \\
\hline NW2 & CW2 & 0.23 & 9,231 & $0.05 \pm 0.02$ & $0.06 \pm 0.02$ & $0.95 \pm 0.01$ & $0.99 \pm 0.00$ \\
& CW3 & 0.23 & 29,522 & $0.05 \pm 0.02$ & $0.09 \pm 0.03$ & $0.95 \pm 0.02$ & $0.86 \pm 0.01$ \\
& CW4 & 0.23 & 61,855 & $0.06 \pm 0.02$ & $0.12 \pm 0.04$ & $0.96 \pm 0.03$ & $0.76 \pm 0.01$ \\
& CW5 & 0.23 & 103,551 & $0.06 \pm 0.02$ & $0.13 \pm 0.04$ & $0.96 \pm 0.03$ & $0.71 \pm 0.01$ \\
& CW6 & 0.23 & 148,269 & $0.06 \pm 0.02$ & $0.15 \pm 0.04$ & $0.97 \pm 0.05$ & $0.66 \pm 0.02$ \\
& CW7 & 0.23 & 204,993 & $0.06 \pm 0.02$ & $0.16 \pm 0.05$ & $0.99 \pm 0.06$ & $0.63 \pm 0.02$ \\
\hline
\end{tabular}

${ }^{\mathrm{a}} \mathrm{NW} 2$ = total number of calves weaned by $2 \mathrm{yr}$ of age; CW2 = total weaning weight (kg) by 2 yr of age; CW7 = total weaning weight $(\mathrm{kg})$ by $7 \mathrm{yr}$ of age; $\sigma_{\mathrm{p} 1}^{2}=$ estimate of phenotypic variance for Trait $1 ; \sigma_{\mathrm{p} 2}^{2}=$ estimate of phenotypic variance for Trait $2 ; h_{1}^{2}=$ estimate of heritability for Trait $1 ; h_{2}^{2}=$ estimate of heritability for Trait $2 ; r_{g}=$ estimate of genetic correlation; $r_{e}=$ estimate of environmental correlation.

0.14, and 0.16 for CW2, CW3, CW4, CW5, CW6, and CW7, respectively. Estimates of heritability are smaller than those reported by Arthur and Makarechian (1992), who reported an estimate of $0.27(0.14)$ with a sire model and Arthur et al. (1994), who reported an estimate of 0.30 (0.01) for Hereford cows with an animal model.

Estimates of genetic and environmental correlations were high, ranging from 0.94 to 1.00 and from 0.66 to 0.99 , respectively. Estimates of genetic correlations for CW2 with CW3, CW4, CW5, CW6, and CW7 were 0.99, $0.98,0.96,0.94$, and 0.96 . The pattern was similar for other combinations of $\mathrm{CW}$. As with the estimates of genetic correlations, estimates of environmental correlations decreased with increased length of opportunity group. Estimates of environmental correlations for CW2 with CW3, CW4, CW5, CW6, and CW7 were 0.87 , $0.78,0.73,0.69$, and 0.66 .

Table 5 summarizes estimates of heritability and genetic and environmental correlations for NB2 with NW2 through NW7. In general, estimates of heritability were similar to those from two-trait analyses within type of measurement. Estimates of genetic and environmental correlations were moderate to high. Estimates of genetic correlations ranged from 0.47 between NB2 and NW4 to 0.71 between NB2 and NW2. The general tendency was for estimates of correlations to decrease with increase in length of time between opportunity groups. Estimates of environmental correlations ranged from 0.61 for NB2 with NW7 to 0.68 for NB2 with both NW2 and NW3. As with estimates of genetic correlations, estimates of environmental correlations tended to decline with added length of time between opportunity groups for NW.

Table 6 summarizes estimates of heritability and genetic and environmental correlations for NB2 with CW. In general, estimates of heritability for NB2 and CW were the same as those from two-trait analyses within type of measurement. Estimates of genetic and environmental correlations were moderate to high. Estimates of genetic correlations ranged from 0.55 for NB2 with CW4 to 0.80 for NB2 with CW2. Estimates of genetic correlations tended to decrease with increased time between definitions of opportunity groups. Estimates of environmental correlations ranged between 0.58 for NB2 and CW7 to 0.66 for NB2 with both CW2 and CW3. As with estimates of genetic correlations, estimates of environmental correlations tended to decrease with longer increments of time between definitions of the opportunity groups for CW.

Table 8. Estimates (standard errors) of genetic and environmental changes per year for number born (NB2, NB6), number weaned (NW2, NW6), and cumulative weaning weight (CW2 and CW6) $)^{\mathrm{a}, \mathrm{b}}$

\begin{tabular}{lccccr}
\hline \hline & \multicolumn{5}{c}{ Genetic } \\
\cline { 2 - 5 } Trait & WWL & YWL & IXL & CTL & Environmental \\
\hline NB2 & $0.00 \pm 0.00$ & $0.00 \pm 0.00$ & $0.00 \pm 0.00$ & $0.00 \pm 0.00$ & $0.01 \pm 0.01$ \\
NB6 & $0.02 \pm 0.01$ & $0.01 \pm 0.01$ & $0.02 \pm 0.01$ & $0.01 \pm 0.01$ & $-0.10 \pm 0.02$ \\
NW2 & $0.00 \pm 0.00$ & $0.00 \pm 0.00$ & $0.00 \pm 0.00$ & $0.00 \pm 0.00$ & $0.02 \pm 0.01$ \\
NW6 & $0.02 \pm 0.01$ & $0.01 \pm 0.01$ & $0.01 \pm 0.01$ & $0.02 \pm 0.01$ & $-0.09 \pm 0.01$ \\
CW2 & $0.85 \pm 0.11$ & $0.79 \pm 0.14$ & $0.51 \pm 0.10$ & $0.52 \pm 0.18$ & $1.96 \pm 0.49$ \\
CW6 & $5.01 \pm 1.25$ & $2.64 \pm 1.75$ & $3.67 \pm 1.16$ & $3.33 \pm 2.37$ & $-20.30 \pm 3.52$ \\
\hline
\end{tabular}

${ }^{a}$ Differences in genetic changes between selected lines and CTL were not significant $(P>0.05)$. NB2 = total number of calves born by two years of age; NB 6 = total number of calves born by 6 yrs of age; NW2 = total number of calves weaned by 2 yr of age; NW6 = total number of calves weaned by 6 yr of age; CW2 = total weaning weight $(\mathrm{kg})$ by 2 yr of age; CW6 = total weaning weight $(\mathrm{kg})$ by 6 yr of age.

${ }^{b} \mathrm{WWL}=$ weaning weight line; YWL = yearling weight line; IXL = index line for yearling weight and muscle score; CTL = control line. 
Table 7 summarizes estimates of heritability and genetic and environmental correlations for NW2 with CW. Estimates of heritability for NW2 and CW are in agreement with those from the two-trait analyses within type of measurement. Estimates of genetic correlations ranged from 0.95 to 0.99 and estimates of environmental correlations ranged from 0.99 to 0.63 . Estimates of genetic correlations tended to increase with longer time in opportunity groups for $\mathrm{CW}$, whereas estimates of environmental correlations tended to decrease with increased length of time between definitions of the opportunity groups for CW.

Unfortunately, a lack of research exists about previous estimates of genetic and environmental correlations between measures of lifetime production with different opportunity groups. Arthur and Makarechian (1992) reported estimates of the genetic and phenotypic correlations between total number of calves weaned and total accumulated weaning weight of $1.00(0.01)$ and 0.99 with no standard error reported.

\section{Estimates of Genetic and Environmental Changes}

Table 8 summarizes estimates of genetic and environmental change per year for NB2, NB6, NW2, NW6, CW2, and CW6. The estimates of genetic trend were near to zero for NB2, NB6, NW2, and NW6. Although estimates of genetic trend for CW2 $(P<0.05)$ were less than $1 \mathrm{~kg} /$ year, all were different from zero for all lines. However, estimates of 2 to $5 \mathrm{~kg} /$ year did not differ from zero for CW6 $(P>0.05)$. Genetic trends were not significantly different between selected lines and the control line. The environmental trend was slightly positive for traits measured early in life such as NB2, NW2, and CW2, but the trends were negative for NB6, NW6, and CW6, which are measured later in life.

The small estimates of genetic change for number born and weaned for different opportunity groups is not surprising as no direct selection was applied for these traits in any of the lines. The relatively low response for cumulative weaning weight appears to be low relative to previous reports of direct response to selection for weaning weight in the WWL, and for correlated response in weaning weight from selection for yearling weight in the YWL or the IXL (Koch et al., 1994). The partition of the response by Koch et al. (1994) into direct and maternal components for weaning weight may explain the present result. Reciprocal crosses between the selection lines and the control line produced in the final phase of the selection experiment provided for estimation of response for direct and maternal effects (Koch et al., 2004). For weaning weight, estimates of changes in direct breeding values were $12.3,11.0$, and $7.9 \mathrm{~kg}$ for WWL, YWL, and IXL, respectively. Estimates of changes in maternal breeding values were generally smaller $(1.2,-3.2$, and $7.0 \mathrm{~kg}$ for WWL, YWL, and IXL, respectively). In the current study, CW was a trait of the dam. The estimate of breeding value for weaning weight as a trait of the dam (which would be a major component of $\mathrm{CW}$ ) would include half the direct breeding value plus all the maternal breeding value. The main contribution of the dam to offspring weight included in CW would be her maternal effect. Direct effects transmitted from sire to offspring, would be primarily expressed in source of residual variance. Thus, the estimates of genetic change for $\mathrm{CW}$ would be expected to be small relative to those for weaning weight in previous reports, which were primarily attributable to direct genetic effects.

\section{Implications}

High estimates of genetic correlations among opportunity groups within measures of lifetime production (number of calves born and weaned and cumulative weaning weight) indicate that records through as early as $2 \mathrm{yr}$ of age would predict subsequent cumulative records through $7 \mathrm{yr}$ of age approximately as well as waiting for a measure of lifetime productivity (i.e., prediction of lifetime productivity can be made early in a cow's life). Moderate to high estimates of genetic correlations across three measures of lifetime production indicate that records by 2 to $3 \mathrm{yr}$ of age predict subsequent cumulative records through $7 \mathrm{yr}$ of age nearly as well as later cumulative records. Negligible estimates of genetic change for number of calves born and weaned by 2 and $6 \mathrm{yr}$ of age indicate that successful selection for weights at relatively young weaning or yearling ages had little impact on lifetime reproduction in this experiment. Increases in genetic values for measures of cumulative weaning weight reflect effectiveness of selection for weaning and yearling weights in the selection lines.

\section{Literature Cited}

Arthur, P. F., M. F. Liu, and M. Makarechian. 1994. Estimates of direct and maternal heritabilities for growth and lifetime production traits in beef cows. Pages 225-228 in Proc. 5th World Cong. Genet. Applied Livest. Prod., Guelph, ON, Canada.

Arthur, P. F., and M. Makarechian. 1992. Heritability estimates and correlations among lifetime production traits measured early in life in beef cattle. Pages 400-403 in Proc. Aust. Assoc. Anim. Breed. Genet. University of New England, Armidale, Australia.

Arthur, P. F., M. Makarechian, R. T. Berger, and R. Weingardt. 1993. Longevity and lifetime productivity of cows in a pure Hereford and two multibreed synthetic groups under range conditions. J. Anim. Sci. 71:1142-1147.

Bailey, C. M. 1991. Life span of beef-type Bos taurus and Bos indicus $\times$ Bos taurus females in a dry, temperate climate. J. Anim. Sci. 69:2379-2386.

Boldman, K. G., L. A. Kriese, L. D. Van Vleck, C. P. Van Tassell, and S. D. Kachman. 1995. Page 114 in A Manual for Use of MTDFREML. A Set of Programs to Obtain Estimates of Variances and Covariances. ARS, USDA, Washington, DC.

Cundiff, L. V., R. Nuñez-Dominguez, G. E. Dickerson, K. E. Gregory, and R. M. Koch. 1992. Heterosis for lifetime production in Hereford, Angus, Shorthorn, and crossbred cows. J. Anim. Sci. 70:2397-2410.

Davis, K. C., M. W. Tess, D. D. Kress, D. E. Doornbos, and D. C. Anderson. 1994. Life cycle evaluation of five biological types of beef cattle in a cow-calf range production system: II. Biological and economical performance. J. Anim. Sci. 72:2591-2598. 
Dickerson, G. E. 1970. Efficiency of animal production-molding the biological components. J. Anim. Sci. 30:849-859.

Kachman, S. D. 2001. Analysis of generalized linear mixed model with MATVEC. Available: http://biometry.unl.edu/faculty/steve/ glmm/glmm_ithaca.pdf. Accessed Nov. 18, 2001.

Koch, R. M., L. V. Cundiff, and K. E. Gregory. 1974a. Selection in beef cattle. I. Selection applied and generation interval. J. Anim. Sci. 39:449-458.

Koch, R. M., L. V. Cundiff, and K. E. Gregory. 1974b. Selection in beef cattle. II. Selection response. J. Anim. Sci. 39:459-470.

Koch, R. M., L. V. Cundiff, and K. E. Gregory. 1994. Cumulative selection and genetic change for weaning or yearling weight or for yearling weight plus muscle score in Hereford cattle. J. Anim. Sci. 72:864-885.

Koch, R. M., L. V. Cundiff, K. E. Gregory, and L. D. Van Vleck. 2004. Genetic response to selection for weaning weight or yearling weight or yearling weight and muscle score in Hereford cattle: Efficiency of gain, growth, and carcass characteristics. J. Anim. Sci. 82:668-682.

Lasley, J. F. 1978. Page 429 in Genetics of Livestock Improvement. 3rd ed. Prentice-Hall, Inc., Englewood Cliffs, NJ.

Martinez, G. E., R. M. Koch, L. V. Cundiff, K. E. Gregory, and L. D. Van Vleck. 2003. Genetic parameters for six measures of length of productive life and three measures of lifetime production by six years after first calving for Hereford cows. J. Anim. Sci. 82:1912-1918.

Morris, C. A., R. L. Baker, N. G. Cullen, S. M. Hickey, and J. A. Wilson. 1993. Genetic analyzes of cow lifetime production up to 12 mating years in crossbred beef cattle. Anim. Prod. 57:29-36.

Morris, C. A., R. L. Baker, D. L. Johnson, A. H. Carter, and J. C. Hunter. 1987. Reciprocal crossbreeding of Angus and Hereford cattle. 3. Cow weight, reproduction, maternal performance, and lifetime production. N. Z. J. Agric. Res. 30:453-467.

Nuñez-Dominguez, R., L. V. Cundiff, G. E. Dickerson, K. E. Gregory, and R. M. Koch. 1991. Heterosis for survival and dentition in Hereford, Angus, Shorthorn, and crossbred cows. J. Anim. Sci. 69:1885-1898.

Rendel, J. M., and A. Robertson. 1950. Some aspects of longevity in dairy cows. Emp. J. Exp. Agric. 18:49-56.

Schons, D., W. D. Hohenboken, and J. D. Hall. 1985. Population analysis of a commercial beef cattle herd. J. Anim. Sci. 61:44-54.

Searle, S. R., G. Casella, and C. E. McCulloch. 1992. Variance Components. John Willey \& Sons, Inc., New York.

Tanida, H., W. D. Hohenboken, and S. K. DeNise. 1988. Genetic aspects of longevity in Angus and Hereford cows. J. Anim. Sci. 66:640-647.

Wang, T., R. L. Fernando, and S. D. Kachman. 2002. Matvec User's Guide. Version 1.03. Available: http://statistics.unl.edu/faculty/ steve/software/matvec/. Accessed July 15, 2002. 